\title{
TUF factor binds to the upstream region of the pyruvate decarboxylase structural gene (PDC1) of Saccharomyces cerevisiae
}

\author{
Geraldine Butler $^{1, *}$, Ian W. Dawes ${ }^{2, * *}$, and David J. McConnell ${ }^{1}$ \\ ${ }^{1}$ Department of Genetics, Lincoln Place Gate, Trinity College, Dublin 2, Ireland \\ ${ }^{2}$ Department of Microbiology, University of Edinburgh, West Mains Road, Edinburgh EH9 3JG, UK
}

Received April 25, 1990

\begin{abstract}
Summary. The upstream activation site of the pyruvate decarboxylase gene, PDC1, of Saccharomyces cerevisiae contains an RPG box, and mediates the increase in expression of a $P D C 1-l a c Z$ fusion gene during growth on glucose. Oligonucleotide replacement experiments indicate that the RPG box functions as an absolute activator of expression, but other elements (possibly CTTCC repeats) are required for carbon source regulation, and maximal expression. Gel retardation and oligonucleotide competition experiments suggest that the DNA binding factor TUF interacts with the RPG box in the upstream region of $P D C 1$. Binding of TUF factor is not carbon source dependent in in vitro experiments, and is probably not responsible for glucose induction of $P D C 1$ expression.
\end{abstract}

Key words: Saccharomyces cerevisiae - Gene regulation - TUF - Pyruvate decarboxylase

\section{Introduction}

Promoters of structural genes in Saccharomyces cerevisiae are composed of at least three elements - an mRNA initiation site, at least one TATA box, and an upstream promoter element (for review, see Struhl 1986). Upstream promoter elements are usually defined by short sequences, and are often the recognition sites for regulatory proteins. The same sequence found upstream from several genes can effect coordinate control of these genes (Giniger et al. 1985; Hinnebusch 1988; Oleson et al. 1987; Pfeifer et al. 1987). Recently, a sequence has been

* Present address: Department of Biological Chemistry, University of Michigan Medical School, Ann Arbor, Michigan 48109-0606, USA

** Present address: Department of Biochemistry, University of New South Wales, P.O. Box 1, Kensington, New South Wales, Australia 2033

Offprint requests to: $\mathrm{G}$. Butler identified which may be involved in the control of transcription of a wide variety of genes. The $15 \mathrm{bp}$ sequence was first noted in the upstream region of 16 ribosomal protein genes, and has been named the RPG box, or UAS $_{\text {rpg }}$ (Leer et al. 1985; Teem et al. 1984; Woudt et al. 1987). Deletion of this sequence has been shown to reduce dramatically transcription from the upstream region of the ribosomal protein L25 gene (Woudt et al. 1986). $U_{A A S}$ rpg has been shown to be the recognition site for the DNA binding factor, TUF (Huet et al. 1985; Huet and Sentenac 1987; Vignais et al. 1987). Sequences with homology to $\mathrm{UAS}_{\mathrm{rpg}}$ have now been identified upstream of several yeast genes, including ubiquitin-ribosomal protein fusion genes, the $H M R$ and $H M L$ loci, the $M A T \alpha$ gene, and various glycolytic genes (Buchman et al. 1988a, b; Butler and McConnell 1988; Capieaux et al. 1989; Chambers et al. 1989; Finley et al. 1989; Lue and Kornberg 1987; Nishizawa et al. 1989; Shore and Nasmyth 1987). Proteins (named RAP1 and GRFI) which bind to these sequences have been isolated and are similiar to TUF or possibly identical to it (Buchman et al. 1988a, b; Shore and Nasmyth 1987).

Expression of the pyruvate decarboxylase structural gene, $P D C 1$, is induced 4 - to 30 -fold during growth on fermentable carbon sources such as glucose, compared to non-fermentable carbon sources (Butler and McConnell 1988; Kellermann and Hollenberg 1988; Kellermann et al. 1986; Schmitt et al. 1983). Deletion analysis has been used to map an upstream activation site, $\mathrm{UAS}_{\mathrm{pdc}}$, to between 793 and $535 \mathrm{bp}$ upstream from the translation start site (Butler and McConnell 1988; Kellermann and Hollenberg 1988). $\mathrm{UAS}_{\mathrm{pdc}}$ mediates the response to glucose, and contains a sequence which is homologous to the RPG box (Butler and McConnell 1988). In this paper we describe the identification of yeast proteins which bind to this site and elsewhere in the promoter region. We present evidence that one of these is the TUF factor, suggesting that the $P D C 1$ structural gene is one of several genes under the control of this general transcriptional activator. We also suggest that the RPG 
box is necessary, but not sufficient, for maximal levels of expression of $P D C 1$ on glucose media.

\section{Materials and methods}

Strains and media. S. cerevisiae DBY746 (MATa, his3, leu2-3, leu2-112, trp1-289, ura3-52) was used as a host for transformations. Protein extracts were prepared from either $S$. cerevisiae DBY746, or S. cerevisiae DC5 (MATa, leu2-3, leu2-13, his3, can1). Yeast cultures were grown at $30^{\circ} \mathrm{C}$ in YEP ( $1 \%$ yeast extract, $2 \%$ peptone) with $2 \%$ glucose (YEPD) or $2 \%$ glycerol (YEPG) as carbon source. Yeast transformants were selected on synthetic defined media as described previously (Butler and McConnell 1988). All yeast transformations including intergration events were carried out using the lithium acetate method of Ito et al. (1983). For integration of plasmids, up to $5 \mu \mathrm{g}$ DNA was used per transformation. All integrants were monitored by Southern blotting to ensure a copy number of one (data not shown). $\beta$-Galactosidase assays were carried out on solid media using buffered uracil drop-out plates and $200 \mu 1$ of 5-bromo-4chloro-3-indolyl $\beta$-D-galactopyranoside (X-gal) at $2 \mathrm{mg} /$ $\mathrm{ml}$. The method used for assays from liquid culture (at $\mathrm{OD}_{600}$ of $0.8-1.0$ ) has been described previously (Butler and McConnell 1988). Escherichia coli DB6656 (lacZ 624 (am), trp-49 (am), pyrF::Mu, rps L179, hsd R27) and TG1(K12, $\Delta$ (lac-pro), supE, thi, hsdR, $\mathrm{F}^{\prime}$, tra 136 , pro $A B$, lacI, lac $Z-\Delta M 15$ ) were used for all plasmid manipulations.

Manipulation of DNA. All preparations of plasmids, restriction digests and ligations were carried out essentially as described in Maniatis et al. (1982). Deletion derivatives of the $P D C 1$ promoter were generated using exonuclease BAL 31 as described previously (Butler and McConnell 1988). A synthetic oligonucleotide (R-21)

AGC TT TGCA CCC ATACC TTC

A ACGT GGG TATGG AAG TTCGA

was generated using a Beckman system 200 DNA synthesiser. R-21 contains the RPG box from $U_{A S}$ pdc (underlined) flanked by HindIII sticky ends. Both strands were synthesised, and were annealed in TE buffer (10 mM TRIS-HCl pH 7.6,1 mM EDTA) by incubating at $65^{\circ} \mathrm{C}$ for $5 \mathrm{~min}$ and slowly cooling to room temperature. The oligonucleotide was cloned into the HindIII site at the $5^{\prime}$ end of several $P D C 1-l a c Z$ deletions. Colony hybridization was used to screen for plasmids carrying $\mathrm{R}-21$. The orientation of the cloned oligonucleotide was determined by direct plasmid sequencing (method of D.J. O'Mahony, Trinity College, Dublin), or singlestranded sequencing of a DraI fragment spanning the cloned DNA. R-21 was also cloned into the HindIII site of pUC19 to construct the plasmid pUC-r used in competition studies.

The upstream region of the PDC1 gene was isolated on a $463 \mathrm{bp} \mathrm{HindIII/ScaI} \mathrm{fragment} \mathrm{from} \mathrm{a} \mathrm{deletion} \mathrm{de-}$ rivative, $\Delta-793 . \Delta-793$ is the smallest derivative of a $P D C 1-l a c Z$ fusion with full promoter activity (Butler and McConnell 1988), and contains the RPG box and CTTCC repeats discussed in the text. The fragment was also cloned into the HindIII site of pUC19 to form pUC19-UAS and reisolated by digesting with HindIII and BamHI. A smaller 185 bp HindIII/MaeII fragment which does not contain the CTTCC repeats was also used in gel retardation experiments.

Isolation of proteins. For gel retardation studies, proteins were isolated from yeast cells grown in YEPD and YEPG media to an $\mathrm{OD}_{600}$ of 2-5 by heparin-Sepharose chromatography, using a scaled down version of the method described by Ruet et al. (1984). Fractions were dialysed against storage buffer $(20 \mathrm{mM}$ TRIS- $\mathrm{HCl} \mathrm{pH} 8$, $50 \mathrm{mM} \mathrm{KCl}, 0.1 \mathrm{mM}$ DTT, $1 \mathrm{mM}$ EDTA), and total protein concentrations were determined using the method of Bradford (1976). Samples were stored at $-70^{\circ} \mathrm{C}$ (glycerol fractions were stored for up to 5 months).

Gel retardation. All gel retardation experiments were carried out with DNA fragment end-labelled with $\alpha\left[{ }^{32} \mathrm{P}\right] \mathrm{dCTP}(>3000 \mathrm{Ci} / \mathrm{mmol})$ with Klenow enzyme (Boehringer Mannheim), based on published methods (Fried and Crothers 1981; Garner and Revzin 1981). Approximately $10-20 \mathrm{ng}$ of labelled DNA was added to $10 \mu \mathrm{g}$ cold non-specific competitor DNA (poly dI$\mathrm{dC}$ ), diluted to $100 \mu \mathrm{l}$ with TE buffer, chloroform extracted, and ethanol-precipitated. The DNA was resuspended in $100 \mu \mathrm{l} 2 \times$ footprint buffer $(0.04 \mathrm{M}$ TRIS- $\mathrm{HCl}$ pH 8, $0.14 \mathrm{M} \mathrm{KCl}, 10 \mathrm{mM} \mathrm{MgCl} 2,1 \mathrm{mM} \mathrm{CaCl}_{2}, 1 \mathrm{mM}$ DTT, 0.2 mM EDTA) with $15 \%$ glycerol. Footprint mix $(10 \mu 1)$ was added to varying amounts of cell protein (up to $1 \mu \mathrm{g}$ diluted in sample buffer) and distilled water was added to a total volume of $20 \mu \mathrm{l}$. The mixture was incubated at $25^{\circ} \mathrm{C}$ for $25 \mathrm{~min}$ and then chilled on ice. For specific competition experiments, cold competing DNA was added to the protein samples before addition of the labelled fragment. Half the reaction mix was loaded directly onto polyacrylamide gels $(4.94 \%$ acrylamide, $0.06 \%$ bis-acrylamide) and electrophoresed as described in Huet et al. (1985), except that buffer was recirculated. Gels were dried and autoradiographed at $-70^{\circ} \mathrm{C}$.

Southwestern blotting. The method used was adapted from Miskimins et al. (1985) and Huet and Sentenac (1987). Protein samples were diluted $1: 1$ in $125 \mathrm{mM}$ TRIS-HCl $\mathrm{pH} 6.8,4 \%$ SDS, $10 \%$ 2-mercaptoethanol, $20 \%$ sucrose and $0.004 \%$ bromophenol blue, and where noted were boiled at $95^{\circ} \mathrm{C}$ for $5 \mathrm{~min}$. Samples were electrophoresed in $7.5 \% \mathrm{SDS} /$ polyacrylamide gels at room temperature for $3 \mathrm{~h}$ in $25 \mathrm{mM}$ TRIS- $\mathrm{HCl}, 200 \mathrm{mM}$ glycine, $0.1 \%$ SDS. Half the gel was stained with Coomassie blue. Proteins from the other half were electrophoretically transferred at $4^{\circ} \mathrm{C}$ to nitrocellulose membrane (Schleicher and Schuell) in $25 \mathrm{mM}$ TRIS-HCl, $200 \mathrm{mM}$ glycine buffer, at $70 \mathrm{~mA}$ overnight using a Biorad Transblot cell. The membrane was treated in $5 \% \mathrm{w} / \mathrm{v}$ non-fat milk in $10 \mathrm{mM}$ HEPES $\mathrm{pH} 8$ at room temperature for $1 \mathrm{~h}$ with agitation. Hybridization was carried out in $8 \mathrm{ml}$ binding buffer $(10 \mathrm{mM}$ TRIS- $\mathrm{HCl} \mathrm{pH} 8$, 
$50 \mathrm{mM} \mathrm{NaCl}, 0.1 \mathrm{mM}$ EDTA, $1 \mathrm{mM}$ DTT, $0.25 \%$ nonfat milk) with $1 \mu \mathrm{g}$ end-labelled DNA for $1 \mathrm{~h}$ at $4^{\circ} \mathrm{C}$. The filter was washed in three changes of binding buffer over $30 \mathrm{~min}$ at room temperature, and autoradiographed at $-70^{\circ} \mathrm{C}$ for $2-24 \mathrm{~h}$.

\section{Results}

Cloning of the RPG box into deletion derivatives of PDC1-lacZ

The upstream sequences of the $P D C 1$ gene are shown diagrammatically in Fig. 1. The RPG box lies between 636 and $622 \mathrm{bp}$ upstream of the ATG, and deletions which remove it drastically reduce gene expression (Butler and McConnell 1988). In order to establish more clearly the role of the RPG box, a synthetic oligonucleotide (R-21) containing the RPG box from the upstream region of $P D C 1$ was cloned into the HindIII site at the $5^{\prime}$ end of deletion derivatives of the PDC1-lacZ gene fusion constructed as described previously (Butler and McConnell 1988). The orientation of R-21 was determined by DNA sequencing. The resulting plasmids were integrated into the $S$. cerevisiae genome at the ura3-52 locus, and the effect on expression was assayed directly (Fig. 1). It has also been suggested that the pentamer CTTCC (or the heptamer GCTTCCA (Buchman et al. $1988 \mathrm{~b}$ ) is involved in the regulation of glycolytic genes (Chambers et al. 1988; Ogden et al. 1986). There is a CTTCC sequence overlapping the RPG box in $P D C 1$ at $625 \mathrm{bp}$ upstream from the ATG, a second at $608 \mathrm{bp}$, and two overlapping pentamers at 585 and $581 \mathrm{bp}$. One of these (at position 608) matches the extended GCTTCCA sequence.

The levels of expression of the wild-type construct (YIpDC1-2) are greater than fivefold higher on the fermentable carbon source glucose compared to the nonfermetable glycerol media (Fig. 1). $\beta$-Galactosidase expression in construct $\Delta-628$ is reduced approximately 25-fold on glucose media, compared to the wild-type construction. In this construct all the yeast sequence upstream from -628 has been deleted, including the first 9 bp of the RPG box. Inserting the synthetic RPG box in the minus orientation at the $5^{\prime}$ end of this deletion restores wild-type activity in cells grown on glucose media. The deletion $4-549$ is missing a further $79 \mathrm{bp}$, including the four copies of the CTTCC pentamer, and expression is effectively zero. Inserting the synthetic oligonucleotide in the plus orientation upstream of this deletion results in an increase in expression, to approximately 5.6 units on glucose, and 1.2 units on glycerol media. $\Delta-385$ has a low but detectable level of expression on both carbon sources. Inserting the oligonucleotide in either orientation at the $5^{\prime}$ end of this deletion increases expression 15- to 20 -fold. Thus it is clear that the RPG box does stimulate expression in every case, in cells grown on both glucose and glycerol media. However, maximal levels of glucose-induced expression are not achieved in the absence of the sequences contained the CTTCC pentamer.

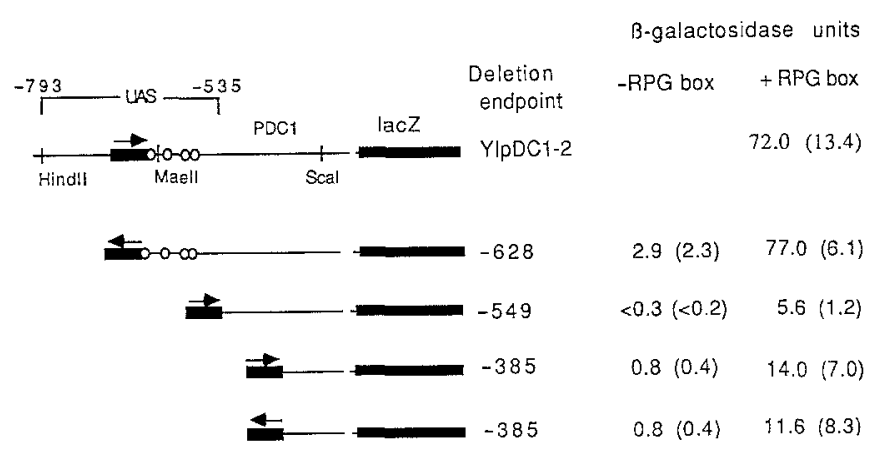

Fig. 1. Effect of RPG box on expression of a PDC1-lacZ fusion. 5 ' deletions of $P D C 1-l a c Z$ were constructed as described previously (Butler and McConnell 1988), and measured $\beta$-galactosidase activities (from cells grown on $2 \%$ glucose) are indicated in the column marked -RPG box. The numbers in parentheses are the levels of expression measured on glycerol media. The synthetic RPG box R-21 was inserted at the $5^{\prime}$ end of these deletions in the orientation indicated, and the resulting levels of expression are shown in the + RPG box column. YIpDC1-2 is the wild-type construct. The activity levels given represent averages of up to four separate measurements. The sequence of the $P D C 1$ promoter has been corrected slightly from that originally published (Butler and McConnell 1988), with the result that deletion derivatives are now numbered with respect to the T of the ATG start codon. The corrected sequence has been submitted to GenBank (Accession no. X14016). - RPG box;-O-CTTCC repeat

Binding of proteins from glucose and glycerol grown cells to the upstream region of $\mathrm{PDC} 1$

The upstream region of the $P D C 1$ structural gene was isolated on a $463 \mathrm{bp} \mathrm{HindIII/ScaI} \mathrm{fragment} \mathrm{from} \mathrm{the}$ $5^{\prime}$ deletion $\triangle-793$. This region contains the UAS ${ }_{\mathrm{pdc}}$ identified by deletion analysis, the putative RPG box and four short direct repeats of the sequence CTTCC (Fig. 1 and Butler and McConnell 1988). Protein fractions were prepared from $S$. cerevisiae DBY746 cells grown in YEPD ( $2 \%$ glucose) by chromatography on a heparinSepharose column was described in Materials and methods. The ability of every second fraction to bind to the upstream region of $P D C 1$ was determined using a gel retardation assay (Fig. 2). Two protein/DNA complexes were identified. Complex I was formed by proteins in fractions 6,8 and 10 , and caused a relatively small shift in the free DNA band. A much more dramatic shift (Complex II) was induced by fractions 18-32, with a peak at approximately fraction 24 .

To determine whether this DNA-binding activity is present in cells grown on gluconeogenic (non-fermentable) carbon sources, a series of fractions prepared from cells grown in YEPG ( $2 \%$ glycerol) was used. Figure 3 shows the binding pattern to the $463 \mathrm{bp} \mathrm{HindIII/ScaI}$ fragment of $P D C 1$. Complex I, seen with the fractions from cells grown on glucose, is not detectable. ComplexII is, however, present in the equivalent fractions (24 28 ) to those obtained for the glucose-grown cells. There is also evidence for a third complex, Complex III, formed by proteins in fractions 32,34 and 36 . 


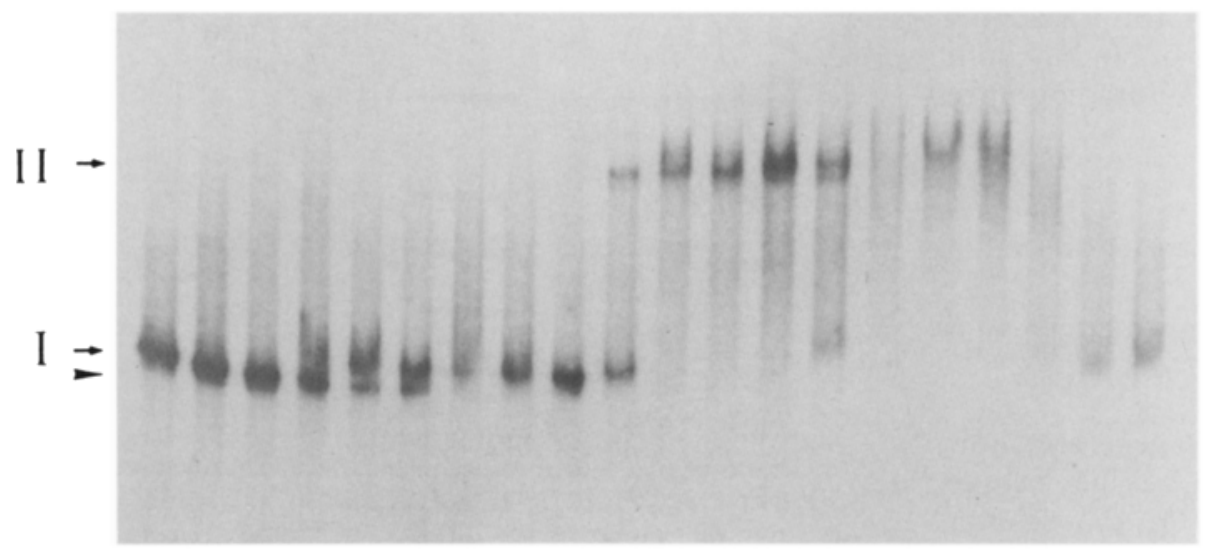

$046 \quad 810121416182022242628303234363840$

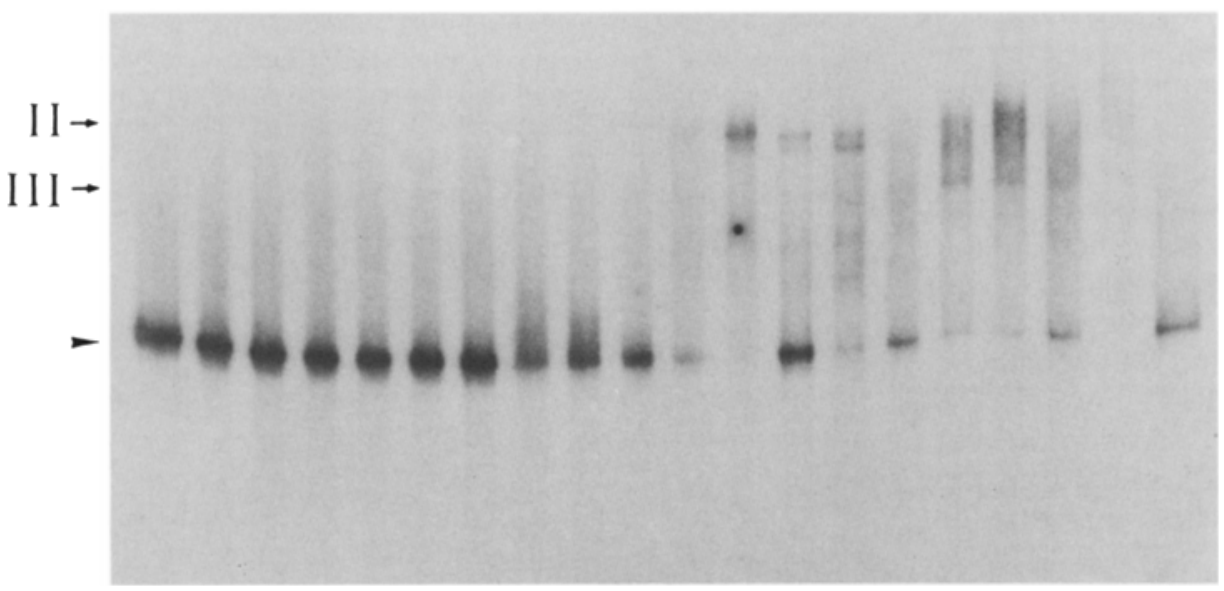

Fig. 2. Binding of fractions from glucose-grown cells to the upstream region of $P D C 1$. A total of $20 \mathrm{ng}$ of the $463 \mathrm{bp} \mathrm{HindIII/Scal} \mathrm{fragment} \mathrm{from} \mathrm{the}$ promoter region of $P D C 1$, end-labelled with $\alpha\left[{ }^{32} \mathrm{P}\right] \mathrm{dCTP}$, and $10 \mu \mathrm{g}$ poly $\mathrm{dI}-\mathrm{dC}$ was used for 20 reactions. Lane 0 contains free DNA; other lanes represent the addition of $0.7 \mu \mathrm{g}$ of protein from fractions prepared from glucose-grown cells (fraction numbers are shown). Free DNA is marked with an arrowhead, and retarded complexes with arrows. Reactions were analysed by gel electrophoresis in a $5 \%$ polyacrylamide gel and visualized by autoradiography
Fig. 3. Binding of fractions from glycerol-grown cells to the upstream region of $P D C 1$. Reaction conditions are the same as in Fig. 2, except that protein fractions from extracts isolated from glycerol-grown cells were used. Lane 0: free DNA (HindIII/ScaI fragment). Other lanes represent the addition of $1 \mu \mathrm{g}$ of protein from fractions indicated. Free DNA is indicated with an arrowhead, and retarded protein/DNA complexes with an arrow
Fraction 24 binds to the RPG box in the upstream region of PDC1

There is some suggestion from Figs. 2 and 3 that binding of proteins in fraction 24 from cells grown in YEPD (called fraction 24-glu) and YEPG-grown cells (called fraction 24-gly) results in the formation of two DNA/ protein species. This is more clearly seen in Fig. 4, where the labelled DNA was incubated with varying amounts of fraction 24-glu. The double complex is seen in all lanes. The upper band (Complex II a) is more intense than the lower band (Complex IIb). As the $463 \mathrm{bp} \mathrm{Hin-}$ $\mathrm{dIII} / S c a$ I fragment used in these experiments includes most of the upstream region of PDC1, the effect of a smaller DNA fragment was investigated to try to locate the binding site more precisely. The HindIII/ScaI fragment was cut with MaeII, producing a 185 bp HindIII/ MaeII fragment, labelled at the HindIII end. MaeII cuts just $3^{\prime}$ to the RPG box, and the fragment contains only one CTTCC sequence (Fig. 1). Fraction 24-glu also binds to this smaller fragment, and again produces two DNA/protein species (Fig. 4, lane d). A similar pattern of retarded complexes was seen using fraction 24-gly (data not shown).

To define further the binding site of fraction 24-glu, binding of the protein to the $463 \mathrm{bp} \mathrm{HindIII/ScaI} \mathrm{frag-}$ ment was carried out in the presence and absence of competitor synthetic oligonucleotide R-21, which contains the RPG box from the upstream region of $P D C 1$. R-21 was cloned into the HindIII site of pUC19 (pUC-r) and used as a competitor at a 0.1- to 10-fold molar ratio in these experiments (Fig. 5). pUC19 with R-21 cloned into the HindIII site (pUC-r) competes for binding of fraction 24-glu at molar ratios of 1 or greater, while pUC19 alone does not (Fig. 5a). The isolated R-21 sequence alone can also compete for binding of fraction 24-glu and fraction 24-gly at similar molar ratios (Fig. 5 b, c).

Binding of fraction 24-glu can be competed with the TUF factor binding site

The protein factor TUF has been found to bind to RPG sequences in the upstream region of several ribosomal 


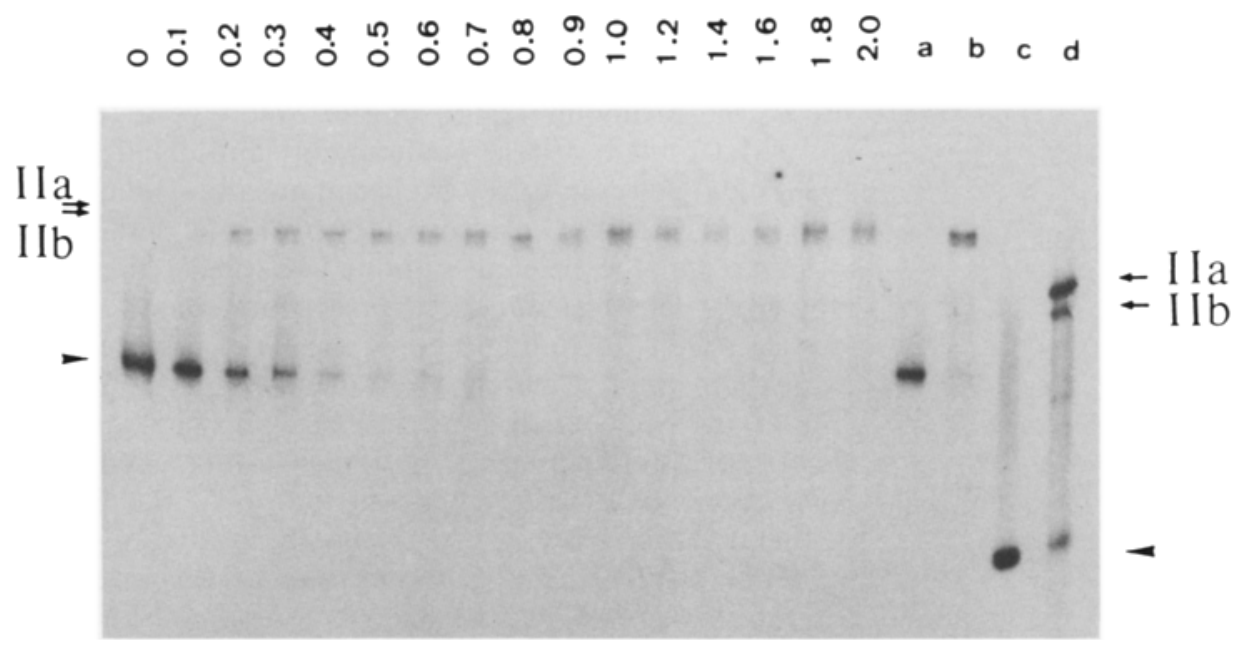

Fig. 4. Binding of fraction 24-glu to the upstream region of PDC1. Reaction conditions are as described (Fig. 2) except that the amount of protein added from fraction 24-glu was varied. Lane 0 : free DNA (463 bp HindIII/ScaI fragment). Protein concentrations, in $\mu \mathrm{g}$, are indicated for other lanes. Lane (a) free DNA (HindIII/
ScaI fragment); lane (b) as lane (a) with $0.7 \mu \mathrm{g}$ fraction 24-glu; lane (c) free DNA (185 bp HindIII/MaeII fragment); lane (d) as lane (c) with $0.7 \mathrm{mg}$ fraction 24-glu. Free DNA is indicated with an arrowhead, and Complex IIa (upper) and IIb (lower) by arrows.
A
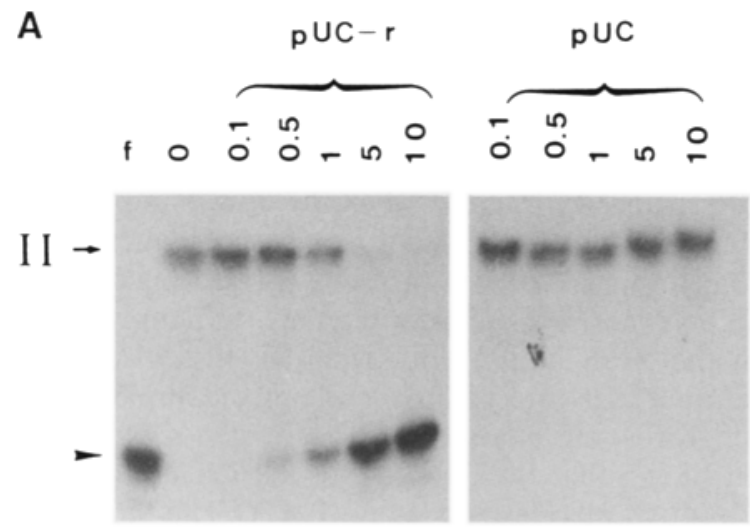

Fig. 5A-C. Binding of fraction 24 to the upstream region of $P D C 1$ can be competed with a synthetic oligonucleotide. The oligonucleotide R-21 cloned into the HindIII site of pUC19 (pUC-r) and pUC19 alone (pUC) were used as competitors of fraction 24-glu binding. Conditions are as described (Fig. 2), except that the labelled DNA was derived from a HindIIJ/BamHI digest of pUC19 containing the $463 \mathrm{bp}$ fragment of the $P D C 1$ promoter. Binding
B
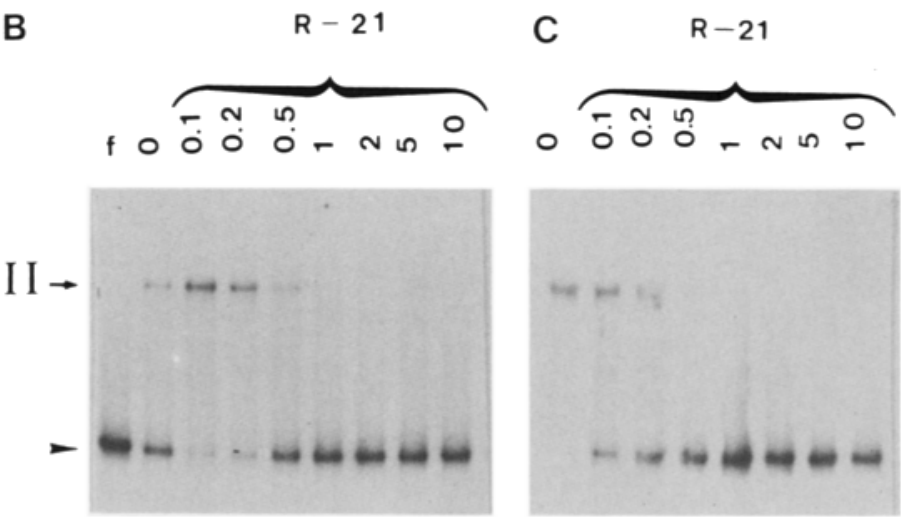

can also be competed with the free oligonucleotide, R-21 (B, C). Cold competitor DNA was added to the protein before the addition of labelled DNA. The molar ratio of the competitor DNA to labelled DNA in each lane is indicated. $\mathbf{A}$ and $\mathbf{B}$ show binding of fraction 24-glu; c shows binding of fraction 24-gly. Lane (f) free DNA (HindIII/BamHI fragment). Free DNA is indicated with an arrowhead, and retarded protein/DNA complex with an arrow protein genes, and to the promoter of the yeast $\mathrm{H}^{+}$. ATPase gene (Huet and Sentenac 1987; Vignais et al. 1987; Capieaux et al. 1989 and references therein). The binding site for the TUF factor was kindly provided by Drs. M-L. Vignais and A. Sentenac (Saclay) on a recombinant BS plasmid, rpg-1, together with a derivative mutated at a single base, rpg-12, which has lost almost all TUF binding ability. Both plasmids were assayed for their ability to compete with the HindIII/BamHI fragment of $P D C 1$ for binding of fraction 24-glu (Fig. 6). Rpg-1 can inhibit binding to the PDCt DNA at molar ratios of 0.5 or greater, while rpg- 12 competes to a much lesser degree even at a molar ratio of 10.
The upstream region of $\mathrm{PDC} 1$ binds to a $145 \mathrm{kDa}$ protein in fraction 24-glu

Binding of the upstream region of $P D C 1$ to a specific protein in fraction 24-glu was investigated using the technique of Southwestern blotting (Huet and Sentenac 1987; Miskimins et al. 1985). Protein samples were electrophoresed in duplicate in a $7.5 \% \mathrm{SDS} /$ polyacrylamide gel and electrophoretically transferred to a nitrocellulose filter. The filter was hybridized using the $5^{\prime}$ end-labeled HindIII/BamHI fragment of $P D C 1$ as a probe. A single protein band with an estimated molecular weight of $145 \mathrm{kDa}$ (range from $135-147 \mathrm{kDa}$ on repeated estimates) was detected (Fig. 7). 


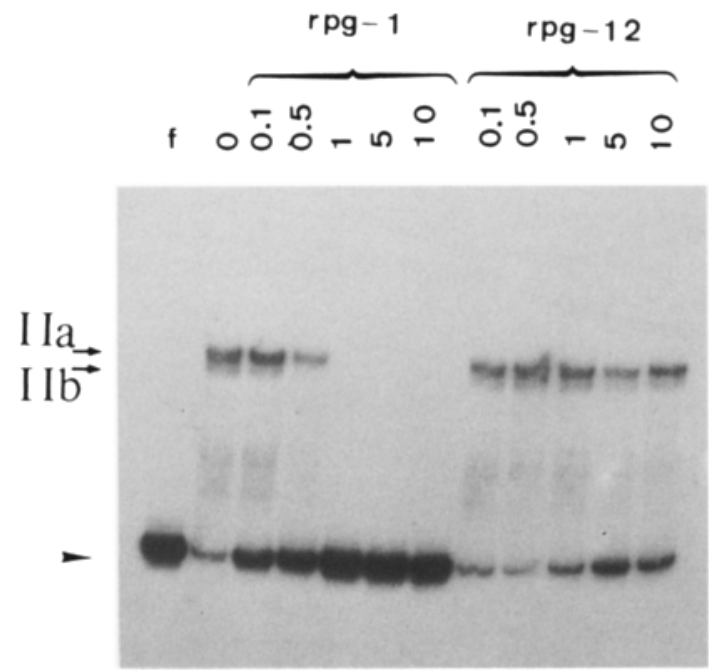

Fig. 6. Binding of fraction 24-glu to the upstream region of $P D C 1$ can be competed by the TUF binding site. The upstream region of $P D C 1$ was isolated on a HindII/Bam HI fragment from pUCUAS. Fraction $24-\mathrm{glu}(0.7 \mu \mathrm{g})$ was added to all lanes except lane (f). The molar ratio of the plasmid carrying the TUF binding site (rpg-1) or mutant derivative (rpg-12) to the labelled DNA is indicated. The arrowhead indicates free DNA, and the arrows the protein/DNA complexes

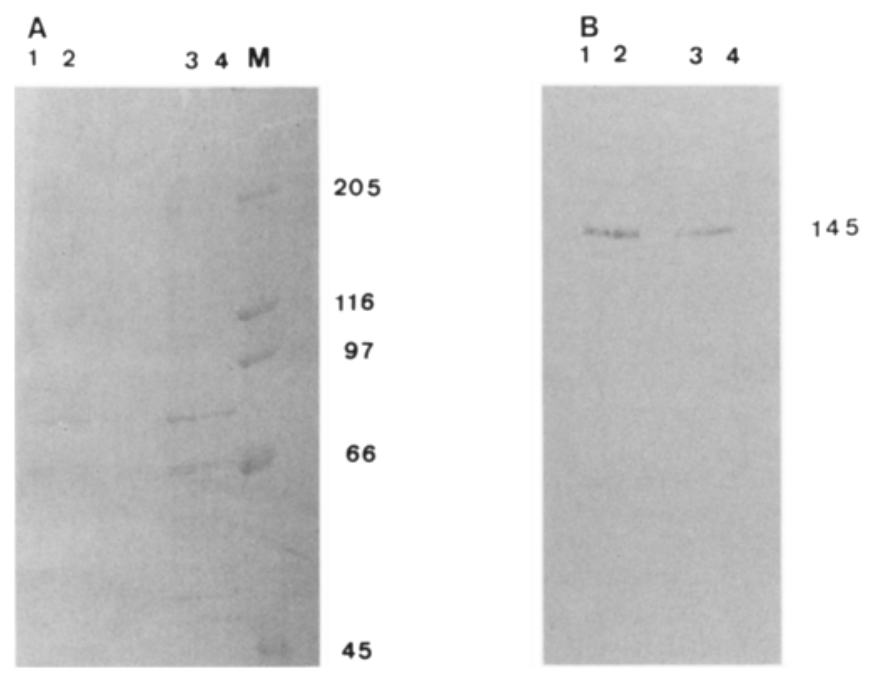

Fig. 7A and B. The upstream region of $P D C 1$ binds to a $145 \mathrm{kDa}$ protein in fraction 24-glu. Various amounts of fraction 24-glu were electrophoresed in duplicate in a $7.5 \%$ SDS polyacrylamide gel. Samples in lanes 1 and 2 were boiled before loading. The gel was divided in two, and half was stained with Coomassie blue (A). Proteins from the other half were electrophoretically transferred to a nitrocellulose filter, and probed with $5^{\prime}$ end-labelled HindIII/ BamHI fragment of pUC-UAS (B). A single protein with an approximate molecular weight of $145 \mathrm{kDa}$ is indicated. Lane $1,10 \mu \mathrm{g}$ fraction 24-glu; lane $2,7.5 \mu \mathrm{g}$ fraction 24 -glu; lanes 3 and 4 are equivalent to lanes 1 and 2 except protein samples were not boiled. Lane $M$, protein molecular weight size standards (Sigma) as indicated

\section{Discussion}

We have described the effect of the RPG box in the upstream region of the $P D C 1$ gene on expression of a yeast $P D C 1-l a c Z$ fusion, and report the identification of protein factors which bind to this region. Deletion analysis has previously identified an upstream activation site in the promoter region of the PDC1 gene (Butler and McConnell 1988; Kellermann and Hollenberg 1988). Data presented by Kellermann and Hollenberg (1988) suggest that all sequences $5^{\prime}$ to the RPG box in $P D C 1$ can be deleted without affecting expression. However, deleting sequences upstream from position -628 of $P D C 1$, including 9 bp of the RPG box, reduces expression approximately 30 -fold on glucose media (Butler and McConnell 1988, and Fig. 1). Wild-type levels of expression can be restored by inserting a synthetic RPG sequence in the minus orientation at the $5^{\prime}$ end of this deletion. We have so far not been able to insert an RPG box in the plus orientation at this site, but the results of replacing the RPG box upstream of deletion 4-385 (Fig. 1) and data reported by Woudt et al. (1986) suggest that RPG boxes can function in either orientation. Clearly the RPG box is important in permitting high levels of expression. However, insertion of a synthetic RPG box upstream of deletions $\Delta-549$ and $\Delta$ 385 , which have less upstream sequence than $\Delta-628$, results in expression levels which are still 5- to 12-fold lower than wild type. In conjunction with the observation that the presence of the RPG box also increases expression on glycerol media (Fig. 1), this suggests that the RPG box may function as a basic activator of expression, but that other sequences (possibly the CTTCC repeats) are required for maximal expression. It is possible that proteins binding to these downstream sequences in PDC1 and other glycolytic promoters (Chambers et al. 1988; Ogden et al. 1986; Stanway et al. 1987) may interact with the RPG binding protein. It is also clear that the promoter structure of $P D C 1$ is more complex than that seen for some ribosomal protein genes, where it has been shown that the RPG box is sufficient to confer glucose induction (Herruer et al. 1987). The small increase in expression resulting from replacement of the RPG box upstream of $\Delta-385$ relative to $\Delta-549$ may be due to the presence of a repressing element around -549 , as previously suggested (Butler and McConnell 1988).

Proteins prepared from cells grown on both fermentable (glucose) and non-fermentable (glycerol) carbon sources can bind to specific sites in the upstream region of $P D C 1$ (Figs. 2, 3). The most dramatic binding identified by gel retardation studies is produced by a protein in fraction 24-glu and fraction 24-gly. The binding factors isolated from both carbon sources are likely to be identical, as both bind specifically to a 463 bp fragment which includes most of the upstream region of $P D C 1$, and to a $185 \mathrm{bp}$ subfragment which contains the RPG box, and result in a similar shift of the free DNA (Figs. 2, 3, 4 and data not shown). The protein appears to bind to the RPG box in $\mathrm{UAS}_{\mathrm{pdc}}$, as a synthetic oligonucleotide (R-21) containing this site can successfully compete for the binding activitites in 24-glu and 24-gly (Fig. 6).

The evidence presented here strongly suggests that the protein in fraction 24 which binds to the upstream region of $P D C 1$ is the same as the TUF factor isolated by Huet et al. (1985) and Huet and Sentenac (1987). 
The recognition site for TUF (RPG box) is very similar to a sequence in UAS $_{\mathrm{pdc}}$ (Butler and McConnell 1988). Moreover, the size of the protein which binds to $\mathrm{UAS}_{\text {pdo }}$ (145 kDa; Fig. 7) as estimated by SDS/polyacrylamide gel electrophoresis is similar to TUF $(150 \mathrm{kDa})$, and binding of fraction 24 can be competed with a plasmid containing the binding site of TUF (Fig. 5).

Binding of fraction 24 from cells grown in both glycerol and glucose results in the formation of two bands in gel retardation assays seen clearly in Fig. 4, both of which can be competed with the TUF-binding site (Fig. 6). Whether this is a result of binding of more than one protein molecule has not been elucidated.

A factor which binds to the RPG box in PDC1 can be detected in fraction 24 from cells grown on both glucose and glycerol media, and competition experiments suggest this is TUF factor. It is therefore unlikely that binding of this factor alone is responsible for the observed induction of expression of a PDC1-lac Z fusion in glucose media, although this must be qualified by noting that it is difficult to measure accurately concentraitons in extracts of cells grown on different media, and that we have not conchusively demonstrated that the binding factors isolated from the two carbon sources are identical. It is also possible, as is suggested by the oligonucleotide replacement experiments (Fig. 1), that TUF factor functions as a basic activator of transcription, and that modulation of expression is mediated by other factors. The binding factor noted in fraction 8-glu but not fraction 8 -gly is one such candidate, and recent evidence suggests that this factor binds to the region containing the CTTCC sequences (G. Butler and D.J. McConnell, unpublished). Clearly the loss of this region causes a significant reduction in expression of $P D C 1$ (Fig. 1). It has also been shown that mutation of the CTTCC sequences in the ENO1 and $P Y K$ promoter regions causes a reduction in expression of lacZ or HIS3 gene fusions under the control of these promoters (Buchman et al. 1988b). The reduced levels of expression of $P D C 1-l a c Z$ on non-fermentable media may also be an effect of repression, rather than lack of induction. This idea is supported by the presence of a binding factor in fraction 30-gly which is not detectable in glucose fractions. It must also be noted that growth on glycerol slightly induces expression of $P D C 1$, whereas little or no expression can be detected on ethanol media (Schmitt et al. 1983). It is possible that TUF factor is present during growth on some, but not all, non-fermentable carbon sources, as studies reported by Chambers et al. (1989) have failed to detect the TUF/RAP1 factor in yeast cells grown on pyruvate as a carbon source.

Several glycolytic enzymes are induced in the presence of fermentable carbon sources such as glucose (Maitra and Lobo 1971). Upstream activation sites which mediate the response to the carbon source have been identified for ENO1 (Cohen et al. 1987), ENO2 (Cohen et al. 1986), PGK (Ogden et al. 1986; Stanway et al. 1987) and $P Y K$ (Nishizawa et al. 1989). There are sequences homologous to the RPG box in many of these activation sites, and also in the upstream region of several other glycolytic genes (Buchman et al. 1988b; Ca- pieaux et al. 1989; Chambers et al. 1989; Lue and Kornberg 1987; Nishizawa et al. 1989). Similar sequences have been identified upstream of the $H M R$ and $H M L$ loci, the $M A T \alpha$ promoter, and the gene coding for yeast plasma membrane $\mathrm{H}^{+}$-ATPase. Binding of the TUF/ RAP1/GRFI protein has been implicated in transcriptional control of several of these genes (Buchman et al. 1988a, b; Capieaux et al. 1989; Chambers et al. 1988, 1989; Shore and Nasmyth 1987). The data presented here suggest that UAS $_{\mathrm{pdc}}$ interacts with TUF factor, and provides further evidence that TUF is indeed a general transcription factor which affects other genes in addition to those coding for ribosomal proteins, and is possibly involved in control of many essential genes (Capieaux et al. 1989; Huet et al. 1985). However, the promoter region of the $P D C 1$ gene must contain other elements which are necessary for maximally induced levels of expression during growth on fermentable carbon sources.

Acknowledgements. We thank Marie-Luce Vignais and André Sentenac (Saclay) for providing the TUF binding site and mutant derivative, Etienne Capicaux (Louvain-la-Neuve), Alistair Chambers (Oxford), and Jurgen Heinisch (Düsseldorf) for access to data before publication, and Ken Wolfe (Dublin) for critical of the reading manuscript. This work was supported by a research grant from the Biotechnology Action Programme of the European Community (Contact No. BAP-0263-IRL).

\section{References}

Bradford MM (1976) A rapid and sensitive method for the quantitation of microgram quantities of protein utilizing the principle of protein dye binding. Anal Biochem 72:248-254

Buchman AR, Kimmerley WJ, Rine J, Kornberg RD (1988a) Two DNA-binding factors recognize specific sequences at silencers, upstream activating sequences, autonomously replicating sequences, and telomeres in Saccharomyces cerevisiae. Mol Cell Biol 8:210-225

Buchman AR, Lue NF, Kornberg RD (1988b) Connections between transcriptional activators, silencers and telomeres as revealed by functional analysis of a yeast DNA-binding protein. Mol Cell Biol 8:5086-5099

Butler G, McConnêll DJ (1988) Identification of an upstream activation site in the pyruvate decarboxylase structural gene (PDC1) of Saccharomyces cerevisiae. Curr Genet 14:405-412

Capieaux E, Vignais M-L, Sentenac A, Goffeau A (1989) The yeast $\mathrm{H}^{+}$-ATPase gene is controlled by the promoter binding factor TUF. J Biol Chem 264:7437-7446

Chambers A, Stanway C, Kingsman AJ, Kingsman SM (1988) The UAS of the yeast $P G K$ gene is composed of multiple functional elements. Nucleic Acids Res 16:8256-8260

Chambers A, Tsang JSH, Stanway C, Kingsman AJ, Kingsman SM (1989) Transcriptional control of the Saccharomyces cerevisiae PGK gene by RAP1. Mol Cell Biol 9:5516-5524

Cohen R, Holland JP, Yokoi T, Holland MJ (1986) Identification of a regulatory region that mediates glucose-dependent induction of the Saccharomyces cerevisiae enolase gene ENO2. Mol Cell Biol 6:2287-2297

Cohen R, Yokoi T, Holland JP, Pepper AE, Holland MJ (1987) Transcription of the constitutively expressed yeast enolase gene $E N O 1$ is mediated by positive and negative cis-acting regulatory sequences. Mol Cell Biol 7:2753-2761

Finley D, Bartel B, Varshavsky A (1989) The tails of ubiquitin precursors are ribosomal proteins whose fusion to ubiquitin facilitates ribosome biogenesis. Nature 338:394-401

Fried M, Crothers DM (1981) Equilibria and kinetics of lac repres- 
sor-operator interactions by polyacrylamide gel electrophoresis. Nucleic Acids Res 9:6505-6524

Garner MM, Revzin A (1981) A gel electrophoresis method for quantifying the binding of proteins to specific DNA regions application to components of the Escherichia coli lactose operon regulatory system. Nucleic Acids Res 9:3047-3060

Giniger E, Varnum SM, Ptashne M (1985) Specific binding of GAL4, a positive regulator protein of yeast. Cell 40:767-774

Herruer MH, Mager WH, Woudt LP, Nieuwint RTM, Wassenaar GM, Groeneveld P, Planta RJ (1987) Transcriptional control of yeast ribosomal protein synthesis during carbon-source upshift. Nucleic Acids Res 15:10133-10144

Hinnebusch AG (1988) Mechanism of gene regulation in the general control of amino acid biosynthesis in Saccharomyces cerevisiae. Microbiol Rev 52:248-273

Huet J, Sentenac A (1987) TUF, the yeast DNA binding factor specific for $\mathrm{UAS}_{\mathrm{rpg}}$ sequences: identification of the protein and its DNA binding domain. Proc Natl Acad Sci USA 84:36483652

Huet J, Cottrelle P, Cool M, Vignais M-L, Thiele D, Marck C, Buhler JM, Sentenac A, Fromagoet P (1985) A general upstream binding factor for genes of the yeast translational apparatus. EMBO J 4:3539-3547

Ito H, Fukuda Y, Murata K, Kimura A (1983) Transformation of intact yeast cells treated with alkali cations. $J$ Bacteriol 153:163-168

Kellermann E, Hollenberg CP (1988) The glucose- and ethanoldependent regulation of $P D C 1$ from Saccharomyces cerevisiae are controlled by two distinct promoter regions. Curr Genet 14:337-344

Kellermann E, Seeboth PG, Hollenberg CP (1986) Analysis of the primary structure and promoter function of a pyruvate decarboxylase gene ( $P D C 1)$ from Saccharomyces cerevisiae. Nucleic Acids Res 14:8963-8977

Leer RJ, Van Raamsdonk-Duin MMC, Mager WH, Planta RJ (1985) Conserved sequences upstream of yeast ribosomal protein genes. Curr Genet 9:273-277

Lue NF, Kornberg RD (1987) Accurate initiation at RNA polymerase II promoters in extracts from Saccharomyces cerevisiae. Proc Natl Acad Sci USA 84:8839-8843

Maitra PK, Lobo Z (1971) A kinetic study of glycolytic enzyme synthesis in yeast. J Biol Chem 246:475-488

Maniatis T, Fritsch EF, Sambrook J (1982) Molecular cloning: a laboratory manual. Cold Spring Harbor Laboratory Press, Cold Spring Harbor, New York

Miskimins WK, Roberts MP, McCelland A, Ruddle FH (1985) Use of a protein blotting procedure and a specific DNA probe to identify nuclear proteins that recognize the promoter region of the transferrin gene. Proc Natl Acad Sci USA 82:6741-6744
Nishizawa M. Araki R, Teranishi Y (1989) Identification of an upstream activating sequence and an upstream repressible sequence of the pyruvate kinase gene of the yeast Saccharomyces cerevisiae. Mol Cell Biol 9:442-451

Ogden JE, Stanway C, Kim S, Mellor J, Kingsman AJ, Kingsman SM (1986) Efficient expression of the Saccharomyces cerevisiae $P G K$ gene depends on an upstream activation sequence, but does not require TATA sequences. Mol Cell Biol 6:4335-4343

Olesen J, Hahn S, Guarente L (1987) Yeast HAP2 and HAP3 activators both bind in the $C Y C 1$ upstream activation site, UAS2, in an interdependent manner. Cell 51:953-961

Pfeifer K, Arcangioli B, Guarente L (1987) Yeast HAP1 activator competes with the factor $\mathrm{RC} 2$ for binding to the upstream activation site UAS1 of the CYC1 gene. Cell 49:9-18

Ruet A, Camier S, Smagowicz W, Sentenac A, Fromageot P (1984) Isolation of a class $\mathrm{C}$ transcription factor which forms a stable complex with tRNA genes. EMBO J 3:343-350

Schmitt HD, Ciriacy M, Zimmermann FK (1983) The synthesis of yeast pyruvate decarboxylase is regulated by large variations in the messenger RNA levels. Mol Gen Genet 192:247-252

Shore D, Nasmyth K (1987) Purification and cloning of a DNA binding protein from yeast that binds to both silencer and activator elements. Cell $51: 721-732$

Stanway C, Mellor J, Ogden JE, Kingsman AJ, Kingsman SM (1987) The UAS of the yeast $P G K$ gene contains functionally distinct domains. Nucleic Acids Res 15:6855-6873

Struhl K (1986) Yeast promoters. In: Reznikoff W, Gold L (eds) Maximizing gene expression. Butterworths, London, pp 35-78

Teem JL, Abovich N, Kaufer NF, Schwindinger WF, Warner JR, Levy A, Woolford J, Leer RJ, van Raamsdonk-Duin MMC, Mager WH, Planta RJ, Schultz L, Friesen JD, Fried H, Rosbach $M$ (1984) A comparison of yeast ribosomal protein gene DNA sequences. Curr Genet 12:8295-8312

Vignais M-L, Woudt LP, Wassenaar GM, Mager WH, Sentenac A, Planta RJ (1987) Specific binding of TUF factor to upstream activation sites of yeast ribosomal protein genes. EMBO J 6:1451-1457

Woudt LP, Smit AB, Mager WH, Planta RJ (1986) Conserved sequence elements upstream of the gene encoding yeast ribosomal protein $\mathrm{L} 25$ are involved in transcription activation. EMBO J 5:1037-1040

Woudt LP, Mager WH, Nieuwint RTM, Wassenaar GM, van der Kuyl AC, Murre JJ, Hockman MFM, Brockhoff PGM, Planta RJ (1987) Analysis of upstream activation sites of yeast ribosomal protein genes. Nucleic Acids Res 15:6037-6048

Communicated by B.J. Kilbey 